\title{
Implicações da SARS-CoV-2 na amamentação
}

\author{
Implications of SARS-CoV-2 on breastfeeding \\ Implicaciones del SARS-CoV-2 em la lactancia
}

Recebido: 05/11/2021 | Revisado: 12/11/2021 | Aceito: 13/11/2021 | Publicado: 24/11/2021

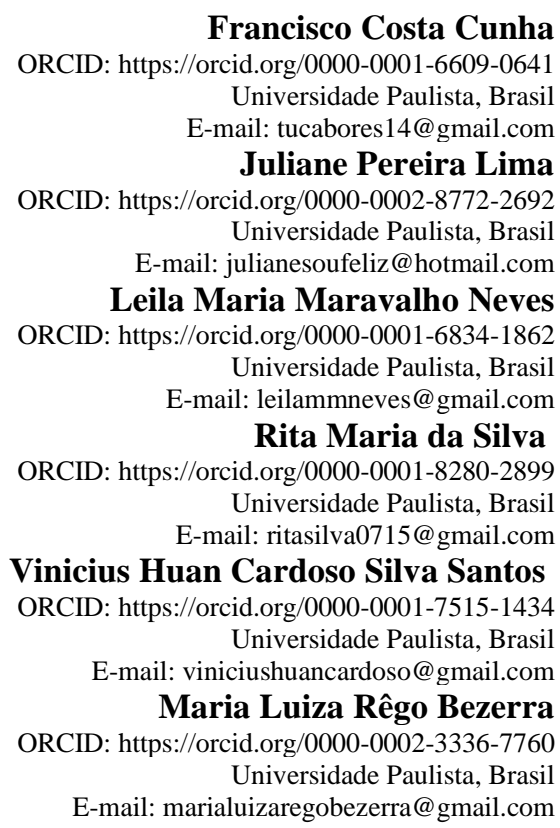

\section{Resumo}

Objetivo: Analisar, através da revisão da literatura, qual a implicação do novo coronavírus na amamentação em tempos de pandemia. Materiais e Métodos: Revisão integrativa em três bases de dados: SciELO; BVS e Google Acadêmico, no idioma português, inglês e espanhol, utilizados palavras indexadas dos seguintes descritores em Ciências e Saúde (DECs): SARS-CoV-2, Covid-19, Aleitamento materno e Cuidados de Enfermagem. Totalizando 30 estudos (27 artigos e 3 referências de órgãos governamentais). Resultados: O aleitamento materno traz muitos benefícios à saúde das crianças e suas mães. A amamentação é a pedra angular da sobrevivência, nutrição e desenvolvimento de bebês e crianças pequenas e da saúde materna. Atualmente, a possível transmissão do vírus pela amamentação ainda está em debate. As recomendações sobre o contato mãe-bebê e a amamentação devem ser baseadas em uma consideração completa não apenas dos riscos potenciais de infecção do bebê por Covid-19, mas também dos riscos de morbidade e mortalidade associados à não amamentação, o uso inadequado de fórmulas infantis leites, bem como os efeitos protetores do contato pele a pele. Conclusão: Com base nas evidências atuais, não foi constatado até o presente momento a transmissão do vírus pelo leite materno. Por esta razão, os benefícios do leite materno superam o risco de interrupção da amamentação e de uma potencial transmissão do coronavírus.

Palavras-chave: SARS-CoV-2; Covid-19; Aleitamento materno; Cuidados de enfermagem.

\begin{abstract}
Objective: To analyze, through a review of the literature, the implication of the new coronavirus in breastfeeding in times of pandemic. Materials and Methods: Integrative review in three databases: SciELO; BVS and Academic Google, in Portuguese, English and Spanish, using indexed words from the following descriptors in Science and Health (DECs): SARS-CoV-2, Covid-19, Breastfeeding and Nursing Care. Totaling 30 studies (27 articles and 3 references from government agencies). Results: Breastfeeding brings many health benefits to children and their mothers. Breastfeeding is the cornerstone of infant and young child survival, nutrition and development, and maternal health. Currently, the possible transmission of the virus through breastfeeding is still under debate. Recommendations on mother-infant contact and breastfeeding should be based on a thorough consideration not only of the potential risks of infection of the baby with Covid-19, but also of the morbidity and mortality risks associated with nonbreastfeeding, the inappropriate use of formulas. infant milks, as well as the protective effects of skin-to-skin contact. Conclusion: Based on current evidence, transmission of the virus through breast milk has not been found to date. For
\end{abstract}


this reason, the benefits of breast milk outweigh the risk of interruption of breastfeeding and potential transmission of the coronavirus.

Keywords: SARS-CoV-2; Covid-19; Breastfeeding; Nursing care.

\begin{abstract}
Resumen
Objetivo: Analizar, a través de una revisión de la literatura, la implicación del nuevo coronavirus en la lactancia materna en tiempos de pandemia. Materiales y Métodos: Revisión integradora en tres bases de datos: SciELO; BVS y Academic Google, en portugués, inglés y español, utilizando palabras indexadas de los siguientes descriptores en Ciencia y Salud (DECs): SARS-CoV-2, Covid-19, Lactancia Materna y Cuidados de Enfermería. En total 30 estudios (27 artículos y 3 referencias de agencias gubernamentales). Resultados: La lactancia materna aporta muchos beneficios para la salud de los niños y sus madres. La lactancia materna es la piedra angular de la supervivencia, la nutrición y el desarrollo del lactante y el niño pequeño, y la salud materna. Actualmente, la posible transmisión del virus a través de la lactancia materna aún está en debate. Las recomendaciones sobre el contacto maternoinfantil y la lactancia materna deben basarse en una consideración exhaustiva no solo de los riesgos potenciales de infección del bebé con Covid-19, sino también de los riesgos de morbilidad y mortalidad asociados con la no lactancia materna, el uso inadecuado de fórmulas. .Leches infantiles, así como los efectos protectores del contacto piel a piel. Conclusión: Con base en la evidencia actual, hasta la fecha no se ha encontrado transmisión del virus a través de la leche materna. Por esta razón, los beneficios de la leche materna superan el riesgo de interrupción de la lactancia y la posible transmisión del coronavirus.
\end{abstract}

Palabras clave: SARS-CoV-2; Covid-19; Lactancia materna; Atención de enfermería.

\title{
1. Introdução
}

Em dezembro de 2019 um vírus da linhagem coronavírus sofreu uma mutação até então desconhecida na época, causando uma síndrome respiratória aguda grave que não era conhecida ainda pela ciência (Opas/OMS, 2021). Os primeiros relatos de casos surgiram em Wuhan, província de Hubei na China e rapidamente disseminou-se para outras províncias do país e também para outros continentes. A Organização Mundial da Saúde (OMS) declarou o início da pandemia em 11 de março de 2020, na época a síndrome viral recebeu o nome de Covid-19, ou seja, (Sars-Cov-2), onde houve a junção do nome do vírus com relação ao ano que surgiu (Opas, 2021). Até então as formas de contágio do vírus são por gotículas, superfícies contaminadas e meios que transmitem aerossóis (Vielas, et al 2021).

Como ainda não tem dados concretos que comprovem a infecção pelo Covid-19, ou melhor, SARS-CoV-2na amamentação, logo os profissionais de saúde orientam que os recém-nascidos devem receber o aleitamento materno de forma eficaz durante os seis primeiros meses vida de forma exclusiva. Assim, conseguimos obter com quer os recém-nascidos adquiram anticorpos para os protegerem de diversas outras doenças, inclusive até mesmo do Covid-19 que ainda estar em estudo pelo mundo (Opas/OMS, 2020).

A OMS recomenda que nas primeiras horas de vida dos recém-nascidos se faça amamentação, pois o leite materno é fonte rica de nutrição e anticorpos que auxiliam no combate de outras infecções oportunistas, como o Covid-19 é um vírus que estar em constantes mutações segundo estudos é fundamental manter o aleitamento nessa época, por isso não se pode dá a real certeza de contágio por essa via (Santos, Amaral, Santos, Carvalho \& Correia, et al 2020)

O presente trabalho justifica-se, devido ser um tema de grande relevância para a sociedade e profissionais de saúde. Destaca-se, que ainda não tem casos concretos que comprovem sobre o risco da infecção pelo novo coronavírus por meio do aleitamento materno, onde as informações estão em constantes mudanças pela ciência, onde muita puérpera não tem o devido conhecimento sobre o aleitamento materno e o risco da infecção pelo novo coronavírus, desse modo, esse estudo trará informações relevantes sobre os riscos de infecção pelo novo coronavírus à puérperas que estão amamentando em tempos de pandemia.

Diante disso, surgiu a seguinte questão norteadora do estudo: É possível haver infecção por Sars-Cov-2 durante a amamentação em tempo de pandemia? 
Para responder ao questionamento acima, o objetivo geral foi identificar a partir de revisão de literatura qual a implicação do novo coronavírus na amamentação em tempos de pandemia. Para isso, utilizou-se os seguintes objetivos específicos: Discorrer sobre o aleitamento materno; buscar meios científicos que façam a correlação entre amamentação e infecção pela SARS-CoV-2 às puérperas em fase de amamentação e sobre o impacto da pandemia na amamentação; verificar as reais evidências de transmissões na fase lactante, mostrando também a importância da orientação precoce e as dificuldades enfrentadas na amamentação.

\section{Metodologia}

Para atingir o objetivo proposto, foi realizado um amplo estudo de revisão integrativa, um método que visa fornece um melhor conhecimento sobre uma determinada questão de pesquisa, para que profissionais qualificados possam avaliá-la criticamente. Além disso, a revisão integrativa tem uma ampla gama de propósitos: definir conceitos, revisar teorias, revisar evidências e analisar questões metodológicas. Portanto, o objetivo original deste método de pesquisa é obter uma compreensão profunda de um dado fenômeno com base em pesquisas anteriores (Mendes, Silveira \& Galvão, 2019).

Assim, o pesquisador pode elaborar a revisão integrativa por meio de diferentes conhecimentos. A pesquisa é denominada como uma síntese porque fornece uma gama ampla de informações sobre um tema/problema, o que constitui um sistema de conhecimento.

Desta forma, os pesquisadores podem preparar uma revisão abrangente para diferentes fins, se concentrando em definições conceituais, revisões teóricas ou análises metodológicas de estudos incluídos com tópicos específicos, conforme preconiza (Mendes, Silveira e Galvão, 2019). Para tanto, foram adotadas 6 (seis) diferentes etapas para estabelecer uma revisão abrangente.

A primeira fase inclui um processo abrangente de revisão e elaboração, começando com a definição do problema e a formulação da hipótese ou problema de pesquisa relacionado à saúde e cuidados. A segunda etapa está intimamente relacionada à etapa anterior, pois o escopo do assunto a ser estudado determina o procedimento de amostragem. A terceira etapa envolve a definição das informações a serem extraídas da pesquisa selecionada e o uso de ferramentas para coletar e sintetizar as informações-chave. A quarta etapa a equivale a analisar os dados em uma pesquisa de rotina, na qual são utilizadas ferramentas apropriadas. A quinta etapa corresponde à etapa de discussão dos principais resultados da pesquisa convencional. A sexta e última etapa consiste em incluir informações suficientes na revisão abrangente para permitir que os leitores avaliem a relevância dos procedimentos usados na preparação da revisão (Mendes, Silveira \& Galvão, 2019).

\subsection{Estratégia de busca}

Para seleção dos resultados desta pesquisa, foi realizada uma busca nas seguintes bases de dados eletrônicas: Scientific Eletronic Library Online (SCIELO); e a Biblioteca Virtual em Saúde (BVS) e Google Acadêmico. As publicações foram filtradas no idioma português, inglês e espanhol considerando os últimos 2 anos (2019-2021). Para realizar a busca foram utilizadas palavras indexadas dos seguintes descritores em Ciências e Saúde (DECs): SARS-CoV-2, Covid-19, Aleitamento materno e Cuidados de Enfermagem.

Dessa forma, foram criadas combinações entre os descritores e/ ou palavras-chave que deram origem às estratégias de busca descritas a seguir. 
Quadro 1: Estratégia de Busca, Brasília-DF, 2021.

\begin{tabular}{|c|c|}
\hline SCIELO & $\begin{array}{c}\text { (Sars-cov-2 OR Covid-19 OR Breastfeeding OR Nursing care OR "Aleitamento materno") AND } \\
\text { (nursing OR nurse\$ OR enfermagem OR enfermeira\$) }\end{array}$ \\
\hline BVS & $\begin{array}{c}\text { ("Sars-cov-2" [MeSH Terms] OR "Covid-19" [All Fields] OR entrepreneurs [All Fields] OR } \\
\text { entrepreneurial [All Fields] OR Breastfeeding [All Fields] OR i Nursing care [All Fields]) AND } \\
\text { ("nursing" [Subheading] OR "nursing" [All Fields] OR "nursing” [MeSH Terms] OR "nurses" } \\
\text { [MeSH Terms] OR "nurses" [All Fields] OR "nurse" [All Fields]) AND (English [lang] OR } \\
\text { Portuguese [lang] OR Spanish [lang]) }\end{array}$ \\
\hline $\begin{array}{c}\text { Google } \\
\text { Acadêmico }\end{array}$ & $\begin{array}{c}\text { ((Sars-cov-2 OR Covid-19 OR Aleitamento materno OR Cuidados de Enfermagem)) AND } \\
\text { ((Enfermagem OR Enfermeiros)) }\end{array}$ \\
\hline
\end{tabular}

Fonte: Costa et al. (2021).

\subsection{Coleta e análise de dados}

A princípio, foram identificados 18.152 estudos através da coleta de dados, nos quais foram submetidos a primeira etapa de avaliação utilizando os critérios de inclusão e exclusão previamente definidos no protocolo de pesquisa. No intuito de selecionar os estudos, foram utilizados os seguintes os critérios de inclusão: artigos publicados nos últimos 2 anos entre 2019 a 2021, artigos com acesso livre e pagos; a partir dos Descritores em Ciências da Saúde (DECS): Sars-cov-2, Covid-19, Aleitamento materno e Cuidados de Enfermagem. Foram excluídos: artigos anteriores a 2019; trabalhos que não foram publicados entre o período escolhido para estar pesquisa; artigos incompletos, artigos de opinião, comentários, monografias, teses, série de casos e aqueles que não contemplaram o objetivo proposto pelo estudo.

Para essa Revisão a busca da literatura ocorreu entre 2020 e 2021, onde foi realizada uma ampla revisão das evidências científicas para a construção deste trabalho, buscou-se evidências científicas relacionadas ao risco de infecção por Sars-cov-2 durante a amamentação em época de pandemia. Portanto, os artigos científicos aqui estudados são a base para o desenvolvimento científico deste trabalho, que se baseia na pesquisa científica.

Assim obteve-se, na plataforma SCIELO 115 artigos, mas somente 13 foram utilizados; na plataforma BVS foram encontrados 43 artigos, mas somente 6 foram utilizados e na plataforma Google Acadêmico foram encontrados 224 artigos, e somente 8 artigos foram utilizados, além disso foram utilizadas 2 referências da Organização Pan-Americana da Saúde/Organização Mundial de Saúde, bem como, 1 nota técnica do Ministério da Saúde.

Totalizado ao final da primeira etapa 384 estudos. Na segunda etapa, os 384 estudos foram lidos os resumos a fim de identificar aqueles que responderam de forma satisfatória à questão de pesquisa e/ou foram relevantes para o objetivo do estudo. Totalizando assim, 30 estudos (13 artigos da Scielo, 6 artigos da BVS, 8 artigos do Google Acadêmico e 2 referências da Organização Pan-Americana da Saúde/Organização Mundial de Saúde, bem como, 1 nota técnica do Ministério da Saúde) respectivamente 27 artigos e 3 referências de órgãos governamentais abordaram sobre o tema da pesquisa e foram utilizados para ilustrar este trabalho, conforme mostra a Figura 1. 
Figura 1: Fluxograma coleta e análise dos dados. Brasília-DF, 2021.

\section{ESTRATÉGIA DE BUSCA}

\begin{tabular}{|c|c|c|c|}
\hline \multicolumn{3}{|c|}{ Coleta de Dados } \\
\hline \multicolumn{3}{|c|}{ Total de 18.152 estudos } \\
\hline SCIELO & BVS & GOOGLAMS E NOTA & TÉCNICA \\
\hline 850 & 100 & ACADÊMICO & 3 \\
\hline
\end{tabular}

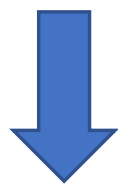

PRIMEIRA ETAPA - 384 ESTUDOS

\begin{tabular}{|c|c|c|c|}
\hline \multirow{2}{*}{ SCIELO } & \multirow{2}{*}{ BVS } & $\begin{array}{c}\text { GOOGLE } \\
\text { ACADÊMICO }\end{array}$ & $\begin{array}{c}\text { OPAS/OMS E NOTA } \\
\text { TÉCNICA }\end{array}$ \\
\hline 115 & 43 & 224 & 3 \\
\hline
\end{tabular}

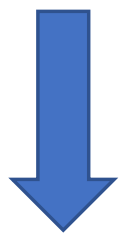

Problemática: É possível haver infecção por SarsCov-2 durante a amamentação em tempo de nandemia?

\begin{tabular}{|c|c|c|c|}
\hline \multicolumn{5}{|c|}{ SEGUNDA ETAPA - 30 ESTUDOS } \\
\hline SCIELO & BVS & GOOGLE ACADÊMICO & $\begin{array}{c}\text { OPAS/OMS E } \\
\text { NOTA } \\
\text { TÉCNICA }\end{array}$ \\
\hline 13 & 6 & 8 & 3 \\
\hline
\end{tabular}

Fonte: Costa et al. (2021).

\section{Resultados}

Os resultados se iniciam, com a descrição dos 30 estudos inclusos nessa revisão. O Quadro 2, ilustra os principais achados na revisão integrativa e características principais dos estudos, quanto: título, ano/periódico, origem, abordagem e 
contexto. A seguir, são apresentadas as três categorias decorrentes dos resultados dos estudos selecionados: aleitamento materno; riscos de infecção para puérperas no pós-parto e a importância do aconselhamento precoce.

Quadro 2: Principais achados.

\begin{tabular}{|c|c|c|c|c|}
\hline Título & Ano /periódico & Origem & Abordagem & Contexto/área \\
\hline Histórico da pandemia de Covid-19. ${ }^{1}$ & $\begin{array}{c}\text { 2019/Organização Pan- } \\
\text { Americana da } \\
\text { Saúde/Organização Mundial } \\
\text { de Saúde }\end{array}$ & Brasil & $\begin{array}{l}\text { Folha informativa sobre } \\
\text { Covid-19 }\end{array}$ & Saúde \\
\hline $\begin{array}{l}\text { Assistência às gestantes e recém-nascidos no contexto da } \\
\text { infecção covid-19: uma revisão sistemática }^{2}\end{array}$ & $\begin{array}{l}\text { 2020/Rev. Latino-Am. } \\
\text { Enfermagem }\end{array}$ & Brasil & Texto & Ciências da Saúde \\
\hline $\begin{array}{l}\text { Aleitamento materno e a doença causada pelo novo } \\
\text { coronavírus (Covid-19). }{ }^{3}\end{array}$ & $\begin{array}{c}\text { 2020/ Organização Pan- } \\
\text { Americana da } \\
\text { Saúde/Organização Mundial } \\
\text { de Saúde }\end{array}$ & Brasil & Informações científicas & Saúde \\
\hline $\begin{array}{l}\text { Aleitamento materno exclusivo em tempos de pandemia da } \\
\qquad \text { Covid-19: revisão integrativa. }{ }^{4}\end{array}$ & $\begin{array}{l}\text { 2021/ Research, Society and } \\
\text { Development. }\end{array}$ & Brasil. & Revisão integrativa. & Saúde \\
\hline $\begin{array}{c}\text { Uso de gerenciador de referências bibliográficas na seleção } \\
\text { dos estudos primários em revisão integrativa. }\end{array}$ & $\begin{array}{l}\text { 2019/ Texto \& Contexto- } \\
\text { Enfermagem. }\end{array}$ & Brasil & Revisão integrativa & Ciências da Saúde \\
\hline $\begin{array}{l}\text { To breastfeed or not to breastfeed? Lack of evidence for the } \\
\text { presence of SARS-CoV-2 in breast milk of pregnant women } \\
\text { with Covid-19. }\end{array}$ & $\begin{array}{l}\text { 2020/Panamerican } \\
\text { Magazine of Public Health }\end{array}$ & EUA & Revisão Sistemática & Ciências da Saúde \\
\hline $\begin{array}{c}\text { Current evidence of SARS-CoV-2 vertical transmission: an } \\
\text { integrative review.? }\end{array}$ & $\begin{array}{l}\text { 2020/ Revista da Associação } \\
\text { Médica Brasileira }\end{array}$ & Brasil & Revisão integrativa & Conhecimento médico \\
\hline $\begin{array}{l}\text { A solidão materna diante das novas orientações em tempos de } \\
\text { SARS-COV-2: um recorte brasileiro. }{ }^{8}\end{array}$ & $\begin{array}{l}\text { 2021/Revista Gaúcha de } \\
\text { Enfermagem }\end{array}$ & Brasil & Estudo teórico reflexivo & Ciências da saúde \\
\hline SARS-CoV-2 and Pregnancy: A Review of the Facts. ${ }^{9}$ & $\begin{array}{l}\text { 2020/Revista Brasileira de } \\
\text { Ginecologia e Obstetrícia }\end{array}$ & Brasil & Revisão & Ciências da Saúde \\
\hline $\begin{array}{l}\text { Recomendações assistenciais à parturiente, puérpera e recém- } \\
\text { nascido durante a pandemia de Covid-19: revisão de escopo. }{ }^{10}\end{array}$ & $\begin{array}{l}\text { 2020/ Revista Latino- } \\
\text { Americana de Enfermagem. }\end{array}$ & Brasil & $\begin{array}{l}\text { Revisão de Escopo com } \\
\text { abordagem sistemática }\end{array}$ & Ciências da Saúde \\
\hline $\begin{array}{l}\text { Probable vertical transmission identified within six hours of } \\
\qquad \text { life. }^{11}\end{array}$ & $\begin{array}{l}\text { 2020/ Revista da Associação } \\
\text { Médica Brasileira }\end{array}$ & Brasil & Estudo de caso & Ciências da Saúde \\
\hline $\begin{array}{l}\text { Covid-19 infection in pregnant women, preterm delivery, birth } \\
\text { weight, and vertical transmission: a systematic review and } \\
\text { meta-analysis. }{ }^{12}\end{array}$ & $\begin{array}{l}\text { 2020/Caderno de Saúde } \\
\text { Pública }\end{array}$ & Brasil & $\begin{array}{l}\text { Revisão sistemátical } \\
\text { metanalise }\end{array}$ & Ciências da Saúde \\
\hline Transmissão vertical e Covid-19: revisão de escopo. ${ }^{13}$ & $\begin{array}{l}\text { 2021/Revista Brasileira de } \\
\text { Enfermagem. }\end{array}$ & Brasil & Revisão de Escopo & Ciências da Saúde \\
\hline $\begin{array}{l}\text { A saúde materno-infantil no contexto da pandemia de Covid- } \\
\text { 19: evidências, recomendações e desafios. }{ }^{14}\end{array}$ & $\begin{array}{l}\text { 2021/Revista Brasileira de } \\
\text { Saúde Materno Infantil }\end{array}$ & Brasil & Revisão narrativa & Ciências da Saúde \\
\hline $\begin{array}{l}\text { Panorama sobre as recomendações para amamentação em } \\
\text { tempos de Covid-19. }{ }^{15}\end{array}$ & $\begin{array}{l}\text { 2020/Journal of Human } \\
\text { Growth and Development. }\end{array}$ & Brasil & Revisão de Escopo & Saúde \\
\hline
\end{tabular}


Research, Society and Development, v. 10, n. 15, e176101522856, 2021

(CC BY 4.0) | ISSN 2525-3409 | DOI: http://dx.doi.org/10.33448/rsd-v10i15.22856

\begin{tabular}{|c|c|c|c|c|}
\hline Coronavírus e recém-nascido: o que se sabe até o momento? ${ }^{16}$ & $\begin{array}{l}\text { 2020/ Sociedade de pediatria } \\
\text { de São Paulo }\end{array}$ & Brasil & Documento científico & Saúde \\
\hline $\begin{array}{l}\text { A amamentação sob a égide de redes de apoio: uma estratégia } \\
\text { facilitadora. }{ }^{17}\end{array}$ & 2020/Esc Anna Nery & Brasil & $\begin{array}{l}\text { Pesquisa qualitativa, } \\
\text { descritiva e exploratória. }\end{array}$ & Saúde \\
\hline $\begin{array}{l}\text { Reflexões sobre o aleitamento materno em tempos de } \\
\text { pandemia por Covid-19.18 }\end{array}$ & $\begin{array}{c}\text { 2020/Rev Soc Bras Enferm } \\
\text { Ped. }\end{array}$ & Brasil. & Revisão de Escopo & Saúde \\
\hline $\begin{array}{l}\text { Amamentação e covid-19: contributos para práticas seguras } \\
\text { /breastfeeding and covid-19: contributions to safe practices } \\
\text { lactancia y covid-19: contribuciones para practicas seguras. }{ }^{19}\end{array}$ & 2020/Millenium & Portugal & Revisão Integrativa & Saúde \\
\hline $\begin{array}{c}\text { Aleitamento Materno e Covid-19: Revisão Sistemática da } \\
\text { Literatura. }^{20}\end{array}$ & $\begin{array}{l}\text { 2020/ Brazilian Journal of } \\
\text { health Review }\end{array}$ & Brasil & Revisão Sistemática & Saúde \\
\hline $\begin{array}{l}\text { Aleitamento materno e terapêutica para a doença coronavírus } \\
\qquad 2019 \text { (Covid-19). }{ }^{21}\end{array}$ & 2020/Residência Pediátrica & Brasil & Artigo Original & Saúde \\
\hline $\begin{array}{l}\text { Plano de cuidados de enfermagem para o aleitamento materno } \\
\text { no contexto da pandemia por Covid-19.2 }\end{array}$ & $\begin{array}{l}\text { 2021/ Revista Enfermagem } \\
\text { Atual In Derme. }\end{array}$ & Brasil & $\begin{array}{c}\text { Ensaio teórico } \\
\text { fundamentado pela revisão } \\
\text { bibliográfica }\end{array}$ & Saúde \\
\hline $\begin{array}{l}\text { Aleitamento materno durante a pandemia da Covid-19: } \\
\qquad \text { Revisão integrativa. }^{23}\end{array}$ & $\begin{array}{l}\text { 2021/Pesquisa, Sociedade e } \\
\text { Desenvolvimento }\end{array}$ & Brasil & Revisão integrativa & Saúde \\
\hline $\begin{array}{l}\text { Boas práticas em atenção perinatal e proteção da } \\
\text { amamentação durante a primeira onda da pandemia Covid-19: } \\
\text { uma análise da situação nacional entre maternidades da IHAC } \\
\text { na Espanha. }{ }^{24}\end{array}$ & $\begin{array}{l}\text { 2021/ Jornal Internacional de } \\
\text { Amamentação. }\end{array}$ & Espanha & Pesquisa transversal & Saúde \\
\hline $\begin{array}{l}\text { Factors Affecting Breastfeeding Practices under Lockdown } \\
\text { during the Covid-19 Pandemic in Thailand: A Cross-Sectional } \\
\qquad \text { Survey. }{ }^{25}\end{array}$ & $\begin{array}{l}\text { 2021/International Journal of } \\
\text { Environmental Research and } \\
\text { Public Health. } 2021\end{array}$ & Tailândia & Estudo Transversal & Saúde \\
\hline $\begin{array}{c}\text { Breast Milk and Breastfeeding of Infants Born to SARS-CoV- } \\
2 \text { Positive Mothers: A Prospective Observational Cohort } \\
\text { Study. }{ }^{26}\end{array}$ & $\begin{array}{l}\text { 2021/ American Journal of } \\
\text { Perinatology. }\end{array}$ & EUA & $\begin{array}{l}\text { Estudo prospectivo de coorte } \\
\text { observacional }\end{array}$ & Saúde \\
\hline $\begin{array}{l}\text { Li M, Chen L, Zhang J, Xiong C, Li X. The SARS-CoV-2 } \\
\text { receptor ACE2 expression of maternal-fetal interface and fetal } \\
\text { organs by single-cell transcriptome study. }{ }^{27}\end{array}$ & 2020/PLoS One & EUA & Revisão & Saúde \\
\hline $\begin{array}{l}\text { SARS-CoV-2 infections and impact of the Covid-19 } \\
\text { pandemic in pregnancy and breasffeeding: Results from an } \\
\text { observational study in primary care in Belgium. }{ }^{28}\end{array}$ & $\begin{array}{l}\text { 2020/ International journal of } \\
\text { environmental research and } \\
\text { public health. }\end{array}$ & Bélgica & Estudo observacional & Saúde da mulher \\
\hline $\begin{array}{l}\text { Breastfeeding and coronavirus disease-2019: Ad interim } \\
\text { indications of the Italian Society of Neonatology endorsed by } \\
\text { the Union of European Neonatal \& Perinatal Societies. }{ }^{29}\end{array}$ & $\begin{array}{l}\text { 2020/ Maternal \& Child } \\
\text { Nutrition. }\end{array}$ & EUA & Abordagem pragmática & Saúde \\
\hline $\begin{array}{c}\text { NOTA TÉCNICA N }{ }^{\circ} \text { 15/2020-COCAM/CGCIVI/ } \\
\text { DAPES / SAPS / MS. }{ }^{30}\end{array}$ & 2020/Ministério da saúde & Brasil & Nota Técnica & Saúde \\
\hline
\end{tabular}

Fonte: Costa et al. (2021). 
Assim, pesquisando através da literatura, quanto ao país de origem dos estudos em questão, a Figura 2 ilustra que, cerca de 73\% (22) dos artigos foram elaborados no Brasil (Opas/OMS,2019-Vielas,2020-Santos,2021-Mendes,2019Oliveira,2020-Rezende,2021-MDS/GOV, et al 2021), 14\% (4) nos Estados Unidos, 3\% (1) Espanha, 3\% (1) Bélgica, 3\% (1) Portugal e 3\% (1) na Tailândia.

Figura 2: Origem. Brasília-DF, 2021.

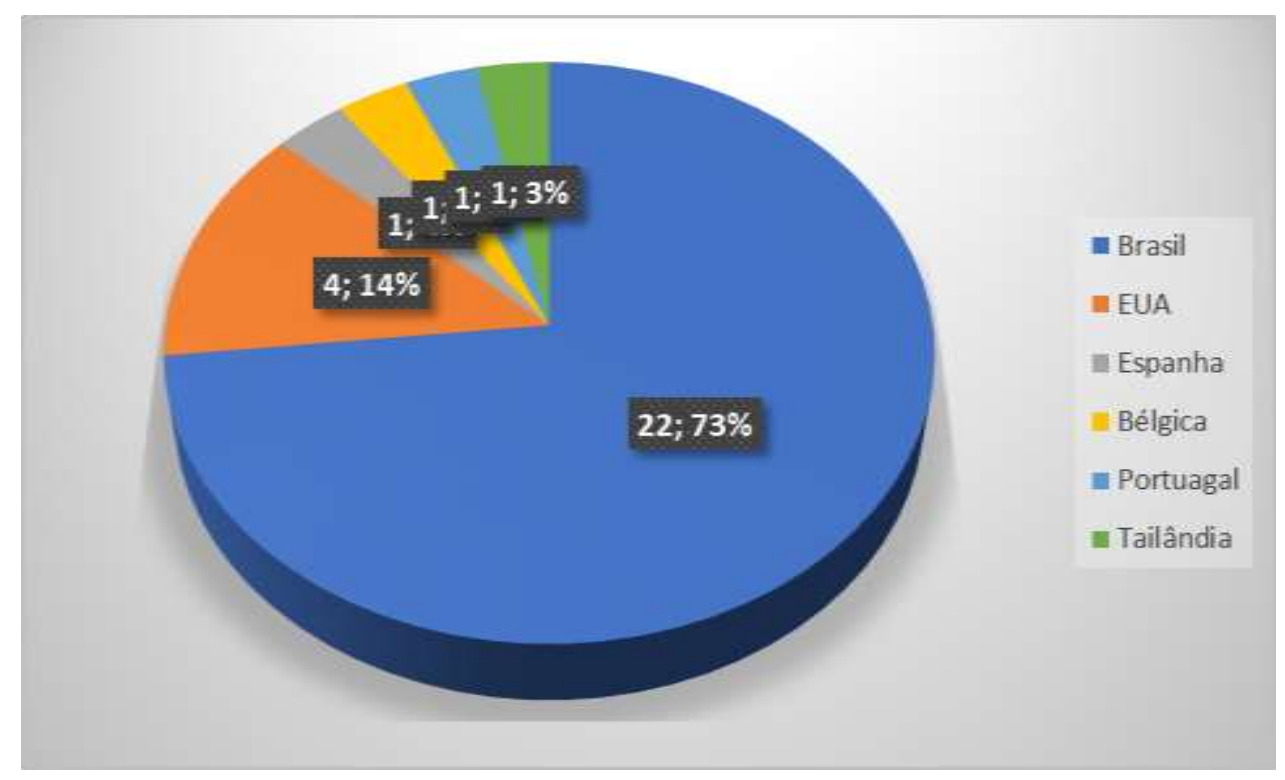

Fonte: Costa et al. (2021).

Em termos de desenho do estudo, observou-se que, os autores utilizaram diferentes métodos sendo: 5 (cinco) estudo de revisão integrativa (Mendes, Santos, Oliveira, Galvão \& Rezende, et al 2021), 4 (quatro) revisão de escopo(Mascarenhas, Oliveira, Mocelin \& Alves, et al 2021), 2 (dois) estudos observacionais (Li, Chen, Ceulemans, Verbakel et al, 2020), 2 (dois) Estudos transversal (Muñoz-Amat, et al, Piankusol, et al,2021), 3 (três) Estudos sistemático(Martins, et al, Melo, Araújo, Silva et al, 2021), 1 (um) estudo qualitativo(Alves, Couto, Barreto \& Quitete,2021), 1(um) estudo prospectivo(Kunjumon' et al, 2021), além de estudos com Ensaio teórico fundamentado pela revisão bibliográfica, Artigo Original, Documento científico, Estudo teórico reflexivo, Revisão, Estudo de caso, Folha informativa sobre Covid-19, Texto, Informações científicas e Nota técnica, todos esses estudos com abordagem qualitativa.

\subsection{Aleitamentos maternos}

O aleitamento materno traz muitos benefícios à saúde das crianças e suas mães (Opas/OMS, 2020). A amamentação é a pedra angular da sobrevivência, nutrição e desenvolvimento de bebês e crianças pequenas e da saúde materna. A amamentação protege neonatos, bebês e crianças contra a morbidade e a morte. O efeito protetor é particularmente forte contra doenças infecciosas, devido à transferência direta de anticorpos, bem como de fatores anti-infecciosos e transferência de longa duração de competência imunológica e memória (Opas/OMS, MDS/GOV \& Santos, et al,2019).

A Opas/Oms estabeleceu uma meta de prevalência de Aleitamento Materno Exclusivo (AME) de 50\% em 2025. É importante entender e usar a definição de aleitamento materno adotada pela Opas/Oms reconhecida mundialmente:

Aleitamento materno exclusivo - quando a criança recebe somente leite materno, direto da mama ou ordenhado, ou leite humano de outra fonte, sem outros líquidos ou sólidos, com exceção de gotas ou xaropes contendo vitaminas, sais de reidratação oral, suplementos minerais ou medicamentos. 
Aleitamento materno predominante - quando a criança recebe, além do leite materno, água ou bebidas à base de água (água adocicada, chás, infusões), sucos de frutas e fluidos rituais.

Aleitamento materno - quando a criança recebe leite materno (direto da mama ou ordenhado), independentemente de receber ou não outros alimentos.

Aleitamento materno complementado - quando a criança recebe, além do leite materno, qualquer alimento sólido ou semissólido com a finalidade de complementá-lo, e não de substituí-lo.

Aleitamento materno misto ou parcial - quando a criança recebe leite materno e outros tipos de leite (Opas/OMS, 2019).

A amamentação é considerada na literatura como o alimento ideal para as crianças, constituindo uma forma primária de promoção da saúde e desenvolvimento da criança, pois se ajusta perfeitamente às necessidades nutricionais e ao crescimento do bebê, protegendo os bebês de infecções, devido à presença de anticorpos. E substâncias imune protetoras. Os estudos também consideram que nenhum outro alimento tem os mesmos benefícios nutricionais, protetores, psicológicos e sociais para o bebê (Silva, et al 2021).

\subsection{Riscos de infecções as puérperas em fase de amamentação}

Atualmente, a possível transmissão do vírus pela amamentação ainda está em debate (Opas/OMS, Oliveira, Pessoa, Melo, et al. 2020). As recomendações sobre o contato mãe-bebê e a amamentação devem ser baseadas em uma consideração completa não apenas dos riscos potenciais de infecção do bebê por Covid-19, mas também dos riscos de morbidade e mortalidade associados à não amamentação, o uso inadequado de fórmulas infantis leites, bem como os efeitos protetores do contato pele a pele. No entanto, surgiram preocupações sobre se as puérperas podem transmitir o vírus SARS-CoV-2 a seus bebês ou crianças pequenas através da amamentação (Opas/Oms, 2021)

Um estudo relatou a resposta imune secretora de imunoglobulina A (sIgA) contra o vírus Covid-19, encontrada em 12 das 15 amostras de leite materno de mães com Covid-19. As implicaçães desta descoberta sobre o efeito, duração e proteção contra Covid-19 para a criança não foram abordadas. Desse modo, as implicações do risco de transmissão precisam ser enquadradas em termos de prevalência de Covid-19 em mães que amamentam e o escopo e gravidade da infecção por Covid19 em bebês quando a transmissão ocorre em comparação com as consequências adversas da separação e uso de substitutos do leite materno e também separação de recém-nascidos e crianças pequenas de mães (Opas/oms,Li,Mds/Gov 2020).

Ainda não está claro se o vírus pode ou não ser transmitido pelo leite materno. O risco de transmissão com base nas práticas de alimentação não foi quantificado, comparado ou modelado em relação aos benefícios da amamentação e da interação mãe-bebê (Opas/Oms, 2019).

\subsection{Importância da orientação precoce}

A amamentação traz benefícios de curto e longo prazo para a mãe e seu filho. Para se beneficiar dos fatores de proteção do leite materno, todos os esforços devem ser feitos para apoiar e permitir o início precoce e imediato da amamentação. (Santos, et al, 2020)

$\mathrm{O}$ recém-nascido tem um sistema imunológico imaturo e o colostro, um poderoso estimulador da imunidade, protege os bebês de infecções por meio de fatores bioativos e anticorpos IgA secretores (Silva, et al 2021). O leite materno com sua fonte abundante de imunoglobulinas, lactoferrina, lisozima e ocitocinas desempenha um papel importante na absorção e engolfamento de micro-organismos prejudiciais e direcionamento de bactérias específicas e fornecendo proteção através da regulação da resposta imune. Todos os itens acima são motivos imperiosos para que todos os bebês recebam apenas leite materno e, de preferência, o leite de suas próprias mães (Oliveira et al 2020).

Deve-se observar que os documentos de orientação provisórios da OMS sobre o manejo de Covid-19 foram informados por diretrizes baseadas em evidências também publicadas pela OMS, como Prevenção e controle de infecções de 
doenças respiratórias agudas com potencial epidêmico e pandêmico na saúde cuidados, bem como informações atuais sobre o Covid-19 (Opas/Oms, 2020).

Medidas gerais de prevenção de infecção devem, portanto, ser sempre tomadas, em todas as circunstâncias, com atenção especial à proteção contra gotículas. Orientações sobre a necessidade de mães que amamentam expostas e infectadas praticarem a higiene das mãos e respiratórias foram fornecidas por muitas organizações internacionais e especialistas na área (Martins et al 2020). Enfermeiros desempenham um papel fundamental no manejo clínico da amamentação e são essenciais para a promoção de sua prática com mulheres/ nutrizes em maternidades. Em sua prática, enfatizam a importância do aleitamento materno, suas vantagens e benefícios para a saúde do bebê (por ser o melhor alimento para eles) e, dessa forma, trabalham em favor do aleitamento materno exclusivo, atendendo políticas públicas sobre atividades de amamentação, no país. A enfermagem brasileira tem desempenhado um papel importante no incentivo de intervenções em saúde em mães lactantes, como estratégia para melhorar as taxas de aleitamento materno exclusivo e diminuir o desmame precoce (Vielas, Mendes, Paixão, Oliveira, Lima, et al 2021).

\section{Discussão}

$\mathrm{Na}$ atual pandemia de SARS-Coronavirus-2 (SARS-CoV-2), é importante identificar todas as vias de transmissão possíveis para prevenir a propagação da doença. Até o momento, todos os relatórios sugerem que a transmissão vertical do SARS-CoV-2 é improvável (Oliveira et al 2020). Fornecer dados confiáveis sobre essa questão pode ter implicações práticas significativas para o conjunto da díade mãe-bebê positiva para SARS-CoV-2 e para o apoio à amamentação. Com base no conhecimento atual de estudos clínicos, parece improvável que o vírus seja transmitido pelo leite materno. No entanto, os dados sobre a detecção da SARS-CoV-2 no leite materno disponíveis na literatura, apresentam um tamanho amostral reduzido e na maioria dos casos limitações metodológicas ( $\mathrm{Li}$, et al 2020).

Com a chegada da pandemia da Covid-19 no Brasil, ouve muitas incertezas em relação a amamentação, pois existem poucos dados sobre as manifestações da Covid-19 em populações específicas, como crianças e mulheres grávidas. Estão sendo desenvolvidas investigações para compreenderem os impactos da Covid-19 em grávidas, atualmente não existem provas de que as grávidas infectadas estejam em maior risco de desenvolvimento de doenças severas do que a população em geral (Czeresnia et al 2020).

Durante os primeiros dias da pandemia, a falta de informações sobre a transmissão vertical de SARS-CoV-2 no leite materno levou à rápida disseminação de desinformação de que os recém-nascidos apresentaram um risco maior de SARSCoV-2 de mães infectadas. O risco de infecção levou a obstáculos adicionais que tornaram a transição para o fornecimento de leite materno e amamentação muito mais difícil durante os estágios iniciais da pandemia (Oliveira et al 2020).

Atualmente, é difícil concluir a partir de relatos de casos se as infecções resultantes ocorreram por transmissão horizontal no nascimento versus transmissão vertical através da placenta. A expressão da enzima conversora de angiotensina 2 (ACE2), o receptor para o vírus SARS-CoV-2, nas células da interface materno-fetal, como as células do estroma, citotrofoblastos e sinciciotrofoblastos, na placenta e outros órgãos fetais pode sugerir que a transmissão vertical é possível e precisa de mais investigação (Oliveira et al 2020). Embora o peso da evidência demonstre a falta de transmissão do vírus SARS-CoV-2, a possibilidade de transmissão transplacentária do SARS-CoV-2 não é clara no momento (Silva,et al 2021).

Existem estudos atuais que mostram a presença de proteínas; ACE2 em tecidos mamários, na qual possibilita a infecção por Sars-Cov-2 no leite materno, segundo essas pesquisas existem o isolamento do vírus no leite materno, porém, houve algumas amostras subsequentes negativas que levaram a pensar em contaminação no momento da coleta, existe outro estudo sobre o Sars-Cov-2 que foi detectado em amostra de leite de uma lactante o vírus, a pesquisa foi feita com amostras colhidas a partir do $10^{\circ}, 12^{\circ}$ é $13^{\circ}$ dia após o nascimento do bebê, onde o recém-nascido foi readmitido com sintomas leve da 
doença. A mãe nesse caso específico fazia todo o procedimento correto, como o uso de máscaras cirúrgicas desde o início dos sintomas, seguia as precauções de segurança necessária, e mesmo com tudo isso a possibilidade da transmissão horizontal é grande, até o momento eles sugerem que o leite materno não é fonte provável da transmissão pelo vírus e que a contaminação pode ocorrer ao nascer ou depois de nascido ( $\mathrm{Li}$, et al 2020).

Existem várias recomendações na literatura sobre parto e obstetrício nos diferentes países afetados pela pandemia, mas não há consenso sobre como se comportar na prática e qualquer realidade pode adotar e priorizar padrões locais ou internacionais ${ }^{(10-14-15)}$. Devido ao risco de contaminação por gotículas, aerossóis e contato durante o trabalho de parto, parto e puerpério, a equipe deve acompanhar de perto o diagnóstico para preparar e seguir adequadamente as recomendações de biossegurança (Martins, et al 2021).

Alguns participantes de pesquisas científicas relataram que durante a pandemia de Covid-19, houve muitas controvérsias sobre a infecção pelo leite materno porque vários países adotaram diferentes protocolos de segurança. Visto os inúmeros protocolos que se tem hoje em dia os pesquisadores chineses não recomendam a amamentação entre o primeiro e o décimo quarto dia, pois não descartam a possibilidade de transmissão pelo leite materno, mesmo que haja polêmica entre o assunto e a ciência, alguns pesquisadores descrevem em suas pesquisas que o leite de doadoras que estão em fase de incubação da doença pode também ter o vírus durante o período e transmitir ${ }^{(2-4-5)}$.

A amamentação melhora a saúde da mãe e do filho, implica benefícios para as famílias e tem um impacto social e econômico positivo. Com base no conhecimento científico da Opas/ Oms, o leite materno de uma mãe com Covid-19 não pode ser considerado um veículo de transmissão, da mesma forma que outras infecções virais respiratórias conhecidas não podem ser (Opas/Oms,2021).

A indicação de precaução para mães com Covid-19 para não amamentar foi proposta por alguns autores, sem evidências sólidas e ignora claramente a importância da amamentação (Cardoso et al 2021). Ao contrário, a atual pandemia de Covid-19 leva-nos a combinar a promoção do aleitamento materno com corretas medidas de controle da infecção, a fim de limitar o contágio por gotículas e pelo contato com as secreções respiratórias de pacientes infectados (inclusive mães que acabaram de dar à luz, segundo Centros para Controle e Prevenção de Doença (do inglês). Centers for Desease Control Prevention-CDC) ${ }^{29}$.

Segundo o CDC, separar a mulher do seu bebê recém-nascido na maternidade não garante menor exposição ao vírus, uma vez que os profissionais de saúde e o ambiente hospitalar também são potenciais transmissores e considerando que essa dupla receberá alta hospitalar, na maioria das vezes, antes da eliminação do vírus, que ocorre em 14 dias, em média (Davanzo et al 2020).

De acordo com a Técnica n ${ }^{\circ} 15$ do Ministério da Saúde, até o momento desta redação, não há evidências científicas de que um nexo de causalidade tenha sido estabelecido entre a transmissão do Sars-CoV-2 e a amamentação. Portanto, não há consenso sobre as recomendações de aleitamento materno para mães portadoras ou em triagem para Covid-19. O Ministério da Saúde leva em consideração os benefícios da amamentação para a saúde de crianças e mulheres, a falta de evidências científicas significativas sobre a transmissão do coronavírus pelo leite materno1 e que não há recomendação de suspensão da amamentação se outras vias respiratórias forem transmitidas por o vírus, recomenda que quando infectado com Sars-CoV-2 requer amamentação desde que a mãe queira amamentar e esteja em um estado clínico adequado (MDS/GOV 2021).

Algumas medidas preventivas podem ser tomadas, incluindo equipamento de proteção individual adequado, recursos para higiene das mãos e fornecimento de informações claras e eficazes às mães e familiares, pois assim, esses meios garantiriam que esses cuidados sejam tomados diariamente. Além dos cuidados pré-estabelecidos, também podem ser criados protocolos que auxiliem às instituições e aos profissionais de saúde, visto que ainda existem incertezas quanto à 
transmissão pelo leite, por isso deve seguir as recomendações de pesquisadores e especialistas qualificados com base em evidências científicas (Martins,et al 2021)

Várias referências incluídas nesta revisão defende a importância do autocuidado e também que as puérperas amamentem mesmo com suspeita da Covid-19, desde que a mulher apresente o desejo de permanecer com a amamentação e que esteja em condições clínicas adequadas para fazê-la. Especialistas orientam que antes de amamentarem a mulher siga meios seguros, para conquistar eficiência no processo de amamentação (Santos, et al 2021)

Dessa forma, o aleitamento materno é um dos principais alimentos que compõem a saúde da criança nos seis primeiros meses de vida, pois possuem anticorpos essências para a construção do sistema imunológico, auxiliando no combate de outras infecções oportunista que podem surgire no decorrer do período. Alguma recomendação em relação ao contato da mãe com o recém-nascido deve ser tomada, caso ela esteja com Covid-19, deve-se basear nas considerações científicas, além dos efeitos protetores do contato da pele, essas informações ajudam a avaliarem as evidências atuais sobre os riscos de transmissões da Covid-19 da mãe infectada para seu bebê através do aleitamento materno (Cardoso, et al 2021)

É importante que se busque orientação profissional de saúde, contudo, isso dependerá se a genitora se sentirá segura a tomar as medidas preventivas sugeridas pelos profissionais de saúde, como higiene das mãos e uso de máscara de proteção. Existem mais benefícios no aleitamento materno do que contraindicação, já que é fonte de vitamina, minerais, capaz de proteger o recém-nascido de várias infecções futuras por isso deve se amamentar mesmo não tendo certezas se a infecção é por essa via ou não (Santos, et al 2021).

A mãe deve ser orientada sobre a técnica de coleta para reduzir o risco de contaminação, seguindo as recomendações dos profissionais de saúde que vem se baseando em evidências científicas, visando uma maior compreensão sobre a relação da Covid-19 com o aleitamento materno a fim de reduzir os riscos de contaminações entre mães e filhos, dessa forma vai seguindo os protocolos disponibilizados pelas autoridades sanitárias até se ter dados concretos e concisos que comprove essa infecção por essa via (Mascarenhas, et al 2021).

Mesmo assim, há pesquisas que em meio ao cenário do novo coronavírus foi recomendado manter o aleitamento materno pelas mulheres com suspeitas de infecções pelo vírus, pois ao mesmo tempo também deve ser adotados cuidados de biossegurança para evitar a transmissão da doença para os recém-nascidos, o coronavírus ainda não foi detectado no leite materno das puérperas e gestantes com confirmação do Covid-19 até o momento, não há evidência de que o vírus seja transmitido através da amamentação ( Pessoa, et al 2020).

A amamentação é muito importante para a saúde do bebê porque contém muitos anticorpos e uma variedade de nutrientes. Alguns pesquisadores acreditam que a amamentação se tornou uma das causas das infecções do Covid-19 aos neonatais por mulheres na fase lactante. A hipótese de possível transmissão pelo leite materno surgiu após o primeiro teste positivo em recém-nascidos em fevereiro de 2020. Nestes casos, a amamentação deve ser coordenada de acordo com a decisão entre o profissional de saúde e a família, portanto todos os procedimentos de segurança são obrigatórios para se ter uma qualidade em todo o processo de amamentação. Recomenda-se usar meios que possam evitar esse contágio de mãe para bebê, pois ainda não se tem estudo atual que comprove até o momento a possibilidade de infecção (Melo \& Araújo 2020).

Portanto, segundo informações científicas Opas/ Oms não está claro se o vírus pode ou não ser transmitido pelo leite materno. O risco de transmissão por meio de práticas alimentares ainda não foi quantificado, comparado ou modelado em termos dos benefícios da amamentação e da promoção do vínculo mãe-filho (Opas/Oms, 2021).

\subsection{Limitações}

Os achados desta revisão foram limitados pela escassez de informações sobre práticas de alimentação infantil e amostras de leite materno testadas, havia informações muito limitadas sobre contato pele a pele, aleitamento materno e 
amamentação exclusiva.

\section{Conclusão}

A elaboração deste estudo teve o objetivo de identificar a partir de revisão de literatura os riscos de infecção pelo novo coronavírus à puérperas que estão amamentando em tempos de pandemia. Verificou-se através da revisão estudada, que a amamentação é a melhor medida de proteção disponível para bebês saudáveis e em risco e suas mães durante a pandemia de Covid-19. Portanto, a amamentação não deve ser interrompida, mães e bebês não devem ser separados e o contato pele a pele não deve ser interrompido. Embora assegurando a normalidade tanto quanto possível, medidas gerais de controle de infecção devem ser implementadas e seguidas de forma estrita. Na mãe exposta ou infectada, a mãe deve tomar proteção adicional contra gotículas usando uma máscara cirúrgica (transparente) ao manusear e alimentar o bebê. Quando as mães estão muito doentes para amamentar, elas ainda devem receber apoio para retirar o leite e o bebê deve ser alimentado por uma pessoa saudável. Bebês amamentados têm a vantagem de receber proteção adicional contra SARS-CoV-2. Com base nas evidências atuais, parece que o vírus não é transmitido pelo leite materno. Por esta razão, os benefícios do leite materno superam o risco de interrupção da amamentação e de uma potencial transmissão do coronavírus.

\section{Referências}

Alves, Y. R., Couto, L. L., Barreto, A. C., Quitete, J. B. (2019). A amamentação sob a égide de redes de apoio: uma estratégia facilitadora. Escola Anna Nery. (2019). https://www.scielo.br/j/ean/a/tKVbQDCHp39cpb9s6tGjCpc/abstract/?lang=pt

Bentlin, M. R., de Almeida, M. F., Marba, S. T., Guinsburg, R., Rebello, C. M., de Siqueira Caldas, J. P., do Nascimento, S. D. Coronavírus E RecémNascido: O Que Se Sabe Até O Momento. Sociedade de Pediatria de São Paulo (SPSP)-Departamento Científico de Neonatologia. São Paulo: SPSP. 2020;3. https://www.spsp.org.br/PDF/SPSP-DC\%20Neonatologia-Covid-vers\%C3\%A3o3-25.09.2020.pdf

Brasil. Ministério da Saúde. NOTA TÉCNICA No 15/2020-COCAM / CGCIVI / DAPES / SAPS / MS. https://egestorab.saude.gov.br/image/?file=20200805_N_NotaTecnicaCovidCocam15_8045946382474299533.pdf

Cardoso, P. C., Sousa, T. M., Rocha, D. D., Menezes, L. R., Santos, L. C. A saúde materno-infantil no contexto da pandemia de Covid-19: evidências, recomendações e desafios. Revista Brasileira de Saúde Materno Infantil. em:https://www.scielo.br/j/rbsmi/a/3MYSwYYhwKnnFbNGQvWCcwH/abstrac $\mathrm{t} /$ ?format=html\&lang=pt

Ceulemans M, Verbakel J. Y, Van Calsteren K, Eerdekens A, Allegaert K, Foulon V. SARS-CoV-2 infections and impact of the Covid-19 pandemic in pregnancy and breastfeeding: Results from an observational study in primary care in Belgium. International journal of environmental research and public health. 17(18):6766. https://www.mdpi.com/829358

Chaves R. G, Lamounier J. A, Santiago L. B. Aleitamento materno e terapêutica para a doença coronavírus 2019 (Covid-19). Residência Pediátrica. 10(2):1-6. https://residenciapediatrica.com.br/exportar-pdf/456/aop_323.pdf

Czeresnia R. M, Trad A. T, Britto I. S, Negrini R, Nomura M. L, Pires P, Costa F. D, Nomura R. M, Ruano R. (2020). SARS-CoV-2 and Pregnancy: A Review of the Facts. Revista Brasileira de Ginecologia e Obstetrícia. https://www.scielo.br/j/rbgo/a/yXGWYQ8kS96vqqbHB8kVc9c/abstract/?lang=en

Davanzo R, Moro G, Sandri F, Agosti M, Moretti C, Mosca F. (2020). Breastfeeding and coronavirus disease-2019: Ad interim indications of the Italian Society of Neonatology endorsed by the Union of European Neonatal \& Perinatal Societies. Maternal \& Child Nutrition, 16(3), e13010. https://onlinelibrary.wiley.com/doi/abs/10.1111/mcn.13010

Galvão D, Batoca Silva E. (2020). Amamentação e Covid-19: contributos para práticas seguras. Millenium. (2):161-8. https://repositorio.ipv.pt/handle/10400.19/6339

Kunjumon B, Wachtel E. V, Lumba R, Quan M, Remon J, Louie M, Verma S, Moffat M. A, Kouba I, Bennett T. A, De Mejia C. M. (2021). Breast Milk and Breastfeeding of Infants Born to SARS-CoV-2 Positive Mothers: A Prospective Observational Cohort Study. American Journal of Perinatology. 38(11):120916. https://www.thieme-connect.com/products/ejournals/html/10.1055/s-0041-1731451

Lima T. J, de Lima M. V, de Oliveira K. K, Ferreira V. O. (2021). Plano de cuidados de enfermagem para o aleitamento materno no contexto da pandemia por Covid-19. Revista Enfermagem Atual In Derme. 19;95(33). http://revistaenfermagematual.com.br/index.php/revista/article/view/985

Li M, Chen L, Zhang J, Xiong C, Li X. (2020). The SARS-CoV-2 receptor ACE2 expression of maternal-fetal interface and fetal organs by single-cell transcriptome study. PLoS One, 15(4), e0230295. https://www.sciencedirect.com/science/article/pii/S2445147921000394

Martins-Filho P. R, Santos V. S, Santos Jr H. P. (2020). To breastfeed or not to breastfeed? Lack of evidence for the presence of SARS-CoV-2 in breast milk of pregnant women with Covid-19. Panamerican Magazine of Public Health. 29, 44: e59. https://www.scielosp.org/article/rpsp/2020.v44/e59/en/. 
Mascarenhas V. H, Caroci-Becker A, Venâncio K. C, Baraldi N. G, Durkin A. C, Riesco M. L. (2020). Recomendações assistenciais à parturiente, puérpera e recém-nascido durante a pandemia de Covid-19: revisão de escopo. Revista Latino-Americana de Enfermagem. 10;28. https://www.scielo.br/j/rlae/a/Nb7Q4btxr6WpbQDVSTjPGww/?lang=pt\&format=html

Melo G. C, Araújo K. C. (2020). Covid-19 infection in pregnant women, preterm delivery, birth weight, and vertical transmission: a systematic review and meta-analysis. Cadernos de saude publica. 17;36:e00087320. https://www.scielosp.org/article/csp/2020.v36n7/e00087320/.

Mendes, K. D. S, Silveira, R. C. D. C. P., Galvão, C. M. (2019). Uso de gerenciador de referências bibliográficas na seleção dos estudos primários em revisão integrativa. Texto \& Contexto-Enfermagem. 28: e 20170204 889-94. https://www.scielo.br/j/tce/a/HZD4WwnbqL8t7YZpdWSjypj/?format=pdf\&lang=pt.

Mocelin H. J, Primo C C, Laignier M R. (2021). Panorama sobre as recomendações para amamentação em tempos de Covid-19. Journal of Human Growth and Development. 30(3):335. http://repositorio.ufes.br/bitstream/10/11651/2/11060-Article\%20Text-36048-1-10-20201015.pdf

Muñoz-Amat B, Pallás-Alonso C. R, Hernández-Aguilar M. T. (2021). Good practices in perinatal care and breastfeeding protection during the first wave of the Covid-19 pandemic: a national situation analysis among BFHI maternity hospitals in Spain. International Breastfeeding Journal. 16 (1): 1-9. https://internationalbreastfeedingjournal.biomedcentral.com/articles/10.1186/s13006-021-00407-y

Oliveira L. V, Silva C. R, Lopes L. P, Agra I K. (2020). Current evidence of SARS-CoV-2 vertical transmission: an integrative review. Revista da Associação Médica Brasileira. 21(66), 130-5. https://www.scielo.br/j/ramb/a/FqtzTs5mNZvh5GCScpnpDSP/abstract/?lang=en/

Oliveira K. F, Oliveira J. F, Wernet M, Paschoini M. C, Ruiz M. T. (2021). Transmissão vertical e Covid-19: revisão de escopo. Revista Brasileira de Enfermagem. 74. https://www.scielo.br/j/reben/a/FXNpRY5WLTyxkFm5GxrgSHp/?format=html\&lang=pt

Organização Pan-americana de Saúde/Organização Mundial de Saúde. Histórico da pandemia de Covid-19. 2019. https://www.paho.org/pt/covid19/historicoda-pandemia-covid-19.

Organização Pan-Americana da Saúde/Organização Mundial de Saúde. Aleitamento materno e a doença causada pelo novo coronavírus (Covid-19).2020. https://iris.paho.org/handle/10665.2/52479\#: :text=As\%20recomenda\%C3\%A7\%C3\%B5es\%20sobre\%20o\%20contato,protetores\%20do\%20contato\%20pele $\% 20$ a.

Paixão G. P, Campos L. M, Carneiro J. B, Fraga C. D. (2020). A solidão materna diante das novas orientações em tempos de SARS-COV-2: um recorte brasileiro. Revista Gaúcha de Enfermagem. 42. https://www.scielo.br/j/rgenf/a/DQ546XgcBsqpcrZ7WXMsKGf/abstract/?lang=pt.

Pessoa F. S., Vale M. .S, Marques P .F, Figuei ra SD, Salgado I A., Mochel R. D. (2020). Probable vertical transmission identified within six hours of life. Revista da Associação Médica Brasileira. 16(66), 1621-4. https://www.scielo.br/j/ramb/a/7BqHhKT6hYhtmMpY5DrT6FG/?format=html\&lang=en

Piankusol C., Sirikul W, Ongprasert K, Siviroj P. (2021). Factors Affecting Breastfeeding Practices under Lockdown during the Covid-19 Pandemic in Thailand: A Cross-Sectional Survey. International Journal of Environmental Research and Public Health. 18(16):8729. https://www.mdpi.com/1234158

Rezende, C. A., Barbosa, T. C., de Sousa Bernardes, I. A., dos Santos, T. I., Lima, M. R., Camilo, A. A., Bernardo, G. J., Oliveira, M. M. (2021). Aleitamento materno durante uma pandemia da Covid-19: Revisão integrativa. Pesquisa, Sociedade e Desenvolvimento. 10 (4): e46310414475-. https://www.rsdjournal.org/index.php/rsd/article/view/14475

Santos, R. C., Amaral, R. C. C., Santos, E., Carvalho, T. V., Correia, T. L. B. V., Costa, C. M., et al. (2021). Aleitamento materno exclusivo em tempos de pandemia da Covid-19: revisão integrativa. Research, Society and Development, $10(3)$ : e28310313167-e28310313167. https://www.rsdjournal.org/index.php/rsd/article/view/13167/11990.

Silva, A. L., Amorim, J. V., Amorim, L. A., da Silva, L. S., Victor, M. P., Guimaraes, M. S., de Prado Costa, V., Barros, M. E. (2020). Aleitamento Materno e Covid-19: Revisão Sistemática da Literatura. Brazilian Journal of Health Review. $11 ; 3$ (5):12289-93. https://www.brazilianjournals.com/index.php/BJHR/article/view/16489

Vilelas, J. M. D. S. (2020). O novo coronavírus e o risco para a saúde das crianças. Rev. Latino-Am. Enfermagem. 28:e3320. https://www.scielo.br/j/rlae/a/ZnYDYvXXBq6N8jJKpMvLKCb/?lang=pt\&format=pdf.

Tacla, M. T., Rossetto, E. G., Perdigão, G. M., Zani, E. M., Silva, I. D. (2020). Reflexões sobre o aleitamento materno em tempos de pandemia por Covid-19. Revista Da Sociedade Brasileira de Enfermeiros Pediatras. 1(20)60-76. https://www.scielo.br/j/ean/a/tKVbQDCHp39cpb9s6tGjCpc/abstract/?lang=pt 